\title{
Preface to the second edition
}

I never imagined in 2001 that the typescript which I had laboured so hard to make as 'cutting edge' as possible would so rapidly be left high and dry by the pace of change. The rate at which environmental thinking and policies have developed over the last seven years has been remarkable. The extent of this transformation not only made a second edition urgently necessary but it meant that the revision turned out to involve a great deal more work than the minor tweaks and updates which I had naively thought would be sufficient. In the end, hardly a paragraph remained untouched. New questions have emerged, old questions have returned with novel twists, and the sense of urgency and importance attached to environmental issues in today's world has reached unprecedented levels. The questions of how we should aim to live as global citizens, and the kind of future which we in Scotland should seek to create for this special part of our shared planetary home, are no longer obscure issues for environmental philosophers but very active and public debates. It has even been suggested by Bishop and Phillips (2004: xvii) that the countryside has not been such a focus of political and public attention since the Corn Law debates of the nineteenth century, and that 'at no time in recent history has the future of the countryside been the subject of such profound uncertainty and anguished debate'. The vigour with which the many debates are being pursued and the rate at which they are evolving are enormously stimulating, but making sense of such a fast-moving and multifaceted field has proved far from straightforward. Regularly I found myself wishing that everything would (please) just stop for a moment and let me write about it! Instead, I have had to try to provide a mid-gallop snapshot.

So what has stayed the same in this edition and what has changed? The overall structure, approach and aims of the book remain as before; the rationale for these is set out in the original preface above. I have also continued to try to write in a way which is academically informed yet widely accessible, and to present debates in as even-handed and dispassionate a fashion as possible (doubtless with mixed success). The major changes in this edition reflect the transformations in environmental debates during the intervening years, both in Scotland and internationally. Back in 2001, strange as it may seem now, very few people were talking about energy issues or windfarms, and so the first edition omitted them entirely, but no book about the Scottish environment would now be complete without an examination of these crucially important matters. Accordingly, energy issues not only have a new chapter of their own but they are also discussed in a range of other contexts (such as forestry, agriculture and water resource 
management). Similarly, although climate change was already a major issue seven years ago, its significance and reach have since extended greatly, and this is reflected in the much greater prominence given to it in a number of chapters. More generally, new environmental policies have been pouring out of Holyrood, Westminster and Brussels as politicians have energetically pursued green agendas, and this has transformed the frameworks in which Scottish environmental management operates. In turn, this has necessitated extensive rewriting and updating of most parts of the text.

Having again worked hard to produce a book which is right up to date, it is dispiriting to realise that, all too soon, it will become a historical document like its predecessor. My hope nevertheless is that, during the few short years before this edition too drifts into obsolescence, it will prove to be a stimulating, informative and engaging text for a wide diversity of readers both within Scotland and further afield.

Charles Warren

St Andrews October 2008 